\title{
Development of a novel conservation treatment of stone monuments with bioactive nanocomposites
}

\author{
Inez Dorothé van der Werf ${ }^{*}$, Nicoletta Ditaranto ${ }^{1,2^{*}}$, Rosaria Anna Picca ${ }^{1}$, Maria Chiara Sportelli ${ }^{1}$ \\ and Luigia Sabbatini $i^{1,2}$
}

\begin{abstract}
In this study a conservation treatment of stone monuments meant for consolidation, protection, and inhibition of biofilm formation is proposed. The method is developed as a part of a systematic investigation aimed at producing nanocomposite coatings able to exert a marked biological activity over a long period of time thanks to their peculiar structure. Zinc oxide nanoparticles, synthesised by means of simple and reproducible electrochemical procedures, are embedded in commercially available and commonly used consolidant/water repellent matrices to obtain nanostructured materials. Products based on tetraethoxysilane and/or polysiloxanes were tested. In a first step the nanomaterials were applied on stone samples and studied with scanning electron microscopy and spectrophotocolorimetry. Then, in situ experimentation was undertaken by applying nanocomposite coatings on the exterior of a 12th-century church in the south of Italy. The performances of the ZnO-nanoparticles based composite coating were compared with a previously investigated copper nanoparticles based material, successfully tested and monitored in situ for more than two years. Finally, preliminary tests on the inhibitory effect on the growth of the fungus Aspergillus niger were also carried out. The results showed that in case of zinc oxide a tenfold higher concentration of nanoparticles as compared with Cu-NPs can be utilized in the matrices without affecting the colour of the stone substrate, which means that the new material should be able to exert a long-lasting biocide activity. Laboratory and in situ tests of the developed innovative nanomaterials yielded very promising, though preliminary, results in terms of chromatic changes, morphological characteristics and bioactivity. Constant monitoring of the coatings will be continued in order to obtain all necessary information on their long term behaviour and inhibition of biological colonisation.
\end{abstract}

Keywords: Biodeterioration, Stone, Nanomaterials, Zinc oxide, Conservation

\section{Background}

Biodeterioration represents one of the major degradation processes of outdoor stone monuments. Chemicalphysical and aesthetic alteration is caused which requires periodical intervention mainly consisting in cleaning, frequently accompanied by other treatments such as consolidation and repair. So far, conservation strategies usually aim to reduce the bioreceptivity, for example by applying

\footnotetext{
*Correspondence: inezdorothe.vanderwerf@uniba.it; nicoletta. ditaranto@uniba.it

1 Dipartimento di Chimica, Università degli Studi di Bari "Aldo Moro", via

Orabona 4, 70125 Bari, Italy

Full list of author information is available at the end of the article
}

protective water repellent coatings, and to remove the biofilm using biocidal products. The latter, commonly quaternary ammonium salts, are unfortunately not capable to inhibit biological recolonisation for long periods of time. Recently, some studies have been focused on innovative strategies consisting in single-step application of a combination of water repellent and homogeneously distributed biocides exerting their action both against residues of biofilm and new colonisation on the surface [1-6]. Similar products are commercially available and have been used in comparative studies to evaluate their effectiveness $[7,8]$. In this context, the ability to progressively release the biocide over time so as to improve its efficacy and thus avoiding repeated treatments is

\section{Chemistry Central}


particularly useful. Quaresima et al. developed $\mathrm{Cu}^{2+}$ based products against the growth of algae and bacteria, capable of a gradual copper release, although not tunable [4]. More recently, a hydrophobic transparent nanocomposite based on $\mathrm{SiO}_{2}-\mathrm{TiO}_{2}$ with self-cleaning properties has been proposed, capable of removing existing biofilms on marble [9]. In another study the preparation and characterisation of antimicrobial surfaces made by combining $\mathrm{Ca}(\mathrm{OH})_{2}$ suspensions with titania or zinc oxide nanoparticles for the conservation of limestone monuments has been reported [10].

The possibility of embedding copper nanoparticles $(\mathrm{Cu}-\mathrm{NPs})$ in inert polymeric matrices to obtain nanostructured bioactive coatings for different applications has been reported by the authors in various studies [11-13]. Indeed, a marked biological activity of these nanomaterials against a wide range of different living organisms (Saccharomyces cerevisiae fungi, Escherichia coli, Staphylococcus aureus, Listeria monocytogenes bacteria and moulds) has been demonstrated. Moreover, it was found that the copper ion release and the resulting bioactivity can be easily tuned by varying the metal NPs loading [12].

Subsequently, the authors have developed specific and appropriate copper-based nanocoatings for application in the field of cultural heritage [14]. In particular, Cu-NPs have been mixed with Estel1100, a silicon based product commonly used as consolidant/water-repellent for stone substrates, in order to obtain a combined system with long-lasting biological activity due to the continuous and controlled release of copper ions that act as biocides. Then, in collaboration with the Opificio delle Pietre Dure Institute (Florence, Italy), the $\mathrm{Cu}-\mathrm{NPs}$ have been used for in situ bioactivity tests. To this purpose aliquots of $\mathrm{Cu}-$ NPs mixed to four types of commercially available consolidant/water-repellent products have been applied to different stone and plaster surfaces located in the archaeological area of Fiesole, and their behaviour has been evaluated for more than two years, showing appreciable performances [8].

However, despite the positive outcome of both the laboratory and in situ evaluation, the dark colour of the $\mathrm{Cu}$-NPs colloids may, indeed, limit their application, especially on light-coloured stone substrates, unless very low amounts are used. Zinc oxide nanoparticles, on the contrary, are white-coloured and should better meet the aesthetic requirements for application in the field of conservation of cultural heritage. ZnO-NPs show very interesting multi-functional properties, such as biocompatibility, chemical stability, and bioactivity, being effective against both Gram positive and Gram negative bacteria and several fungi species $[15,16]$. Although the mechanism of their action is not completely understood
[17-22], their use as biocides is widespread [23-28]. Nevertheless, only recently the use of ZnO-NPs for conservation purposes has been considered. In one study zinc oxide nanoparticles have been proposed for application on oil paintings to inhibit the growth of mould [29]. For stone conservation purposes, as already mentioned, Gómez-Ortíz et al. [10] developed $\mathrm{Ca}(\mathrm{OH})_{2}-\mathrm{ZnO}$ and $\mathrm{Ca}(\mathrm{OH})_{2}-\mathrm{TiO}_{2}$ materials. The $\mathrm{ZnO}$-based systems showed to have the best antifungal properties, being effective both in the dark and under illumination.

Taking into account the multiple favourable characteristics of $\mathrm{ZnO}-\mathrm{NPs}$, it was decided to include them in our study on the development of NPs-based biocides for conservation of stone artefacts. The ZnO-NPs, synthesised by means of a simple and reproducible electrochemical procedure $[30,31]$, are embedded in consolidant/water repellent matrices to obtain nanostructured coatings. Commonly used tetraethoxysilane (TEOS)- and/or siloxanes-based materials (Estel1000, Silo111, and Estel1100) have been selected and the resulting nanomaterials have been fully characterised with XPS in order to determine the amount and speciation of the NPs available on the surface. Moreover, preliminary data [32] obtained by inductively coupled plasma mass spectrometry have shown that zinc is released when the coating is put in contact with acidified water, simulating rain conditions.

In this study, the results on the application of $\mathrm{Cu}-\mathrm{NPs}$ and $\mathrm{ZnO}-\mathrm{NPs}$-based consolidants/water-repellents on stone substrates are presented. The study aims to demonstrate that, in the case of $\mathrm{ZnO}$-based composites, higher NPs loadings can be achieved without affecting the colour of the stone substrates: this is an important issue since the amount of bioactive species which is released by the composite (which is related, in turn, to the durability of the biocide activity) has been shown to depend on the initial concentration $[14,32]$. Preliminary laboratory tests were performed consisting in testing of the nanocoatings on different stone samples; evaluation of chromatic variations and morphological behaviour were carried out with colorimetry and SEM-EDS, respectively.

Then, in situ experimentation was started in a selected area of the 12th-century church of San Leonardo di Siponto (Manfredonia, Italy). Nanocomposites based on ZnO-NPs embedded in ESTEL1100 and SILO111 were applied on the surface of previously cleaned limestone and chromatic changes were measured with spectrophotocolorimetry. Cu-NPs-based nanocoatings, whose behaviour is well known to the authors, were also applied in order to make a comparison between the two materials' performances.

Finally, preliminary experiments assessing the antimicrobial properties of the zinc oxide nanocomposites against Aspergillus niger fungus were also performed. 


\section{Results and discussion} Application on stone specimens

An essential step in the evaluation of new materials and methods to be used for conservation and restoration purposes is to verify whether these are able to fulfil important requirements such as reversibility and compatibility, also from an aesthetic point of view.

Summarising the colorimetric data concerning the $\mathrm{Cu}-\mathrm{NPs} /$ Estel1100 coatings applied on three types of calcareous stone [14], it was observed that the $\Delta \mathrm{E}$ values significantly decrease with the curing of the matrix. Moreover, the chromatic changes vary considerably with the amount of loaded Cu-NPs (ranging from ca. 2 to 23 for $0.02 \% \mathrm{w} / \mathrm{w}$ to $0.14 \% \mathrm{w} / \mathrm{w}$, respectively). In particular, the $\Delta \mathrm{E}$ value of the lowest concentration is very similar to that of pure Estel1100. Furthermore, the chromatic changes seem to be related to the porosity of the stone substrate, being more significant on the compact samples.

As to the whitish zinc oxide nanoparticles embedded in the colourless Silo111 and Estel1000 matrices, no significant chromatic changes are to be expected. Colorimetric measurements were performed on the stone samples before and after application of Estel1000 and Silo111 and their relative nanocomposites containing $0.5 \% \mathrm{w} / \mathrm{w}$ of ZnO-NPs (Table 1).

The $\Delta \mathrm{E}$ values that were obtained immediately after application (at $2 \mathrm{~h}$ ) are relatively high for all samples. After a period of 14 days a significant decrease was observed, and after 38 days the chromatic changes generated by the application of the various materials were shown to diminish substantially. This trend was to be expected because the solvents progressively evaporate and the curing of the TEOS-based consolidant is gradually completed.

Some differences were, however, observed between the three types of stone used for the sample substrates: the $\mathrm{C}$ (Calcare di Altamura) samples exhibit the highest
$\Delta E$ values, whereas the $M$ and $G$ samples (Calcarenite di Gravina) show minor chromatic changes. As already mentioned, this phenomenon has also been observed for the stone samples that had been treated with the $\mathrm{Cu}$ NPs-based materials and might be explained by a better penetration of the applied materials for the porous Calcarenite samples. Further examination of the colorimetric data reveals that major chromatic variations were observed for the Estel1000-based coatings as compared with Silo111. It is important to highlight that the addition of $\mathrm{ZnO}-\mathrm{NPs}$ seems to decrease the chromatic variations caused by application of the consolidants/water-repellents. This can probably be explained by the fact that their whitish colour may to some extent compensate the darkening/"wetting" effect which is normally produced by the application of the conservation products. An exception is, however, formed by the $G$ sample that was treated with Estel1000/ZnO-NPs. In this case the addition of $\mathrm{ZnO}-\mathrm{NPs}$ did not produce a decrease of $\Delta \mathrm{E}$, as observed for all other samples, but, on the contrary, a relatively high value of $\Delta \mathrm{E}$ was observed. This anomaly might be explained by the non-homogeneous structure of this variety of Calcarenite.

Then, morphological characterisation of the stone samples was performed with SEM-EDS. Analyses were performed on surface fragments of the samples treated with Estel1000, Silo111, Estel1000/ZnO-NPs (0.5 \% w/w), and Silo111/ZnO-NPs $(0.5 \% \mathrm{w} / \mathrm{w})$. It was observed that treatment with Silo111 and Estel1000 seems to improve the homogeneity of the stone surface. When comparing the intensity of the Si peak, which can be related to the presence of the silicon-based products, with those of $\mathrm{Ca}$ and $\mathrm{Mg}$ (due to the stone compounds), it was noted that the $\mathrm{Si}$ peak is relatively more abundant for the Estel1000 samples than for the Silo 111 ones. This result suggests a better penetration of Silo111 as compared to Estel1000, which can most likely explain the minor chromatic variations of the Silo111-treated samples. Addition of

Table 1 Colour changes $(\Delta \mathrm{E})$ of the Calcare di Altamura (C), Calcarenite di Gravina from Massafra (M), and Calcarenite di Gravina from Gravina (G) specimens treated with Estel1000 and Silo111 with and without ZnO-NPs (0.5\% w/w) measured at $2 h, 14$ days, and 38 days after application

\begin{tabular}{|c|c|c|c|c|c|c|}
\hline & \multicolumn{2}{|l|}{$2 \mathrm{~h}$} & \multicolumn{2}{|l|}{14 days } & \multicolumn{2}{|l|}{38 days } \\
\hline & Without ZnO & $\mathrm{ZnO} 0.5 \% \mathrm{w} / \mathrm{w}$ & Without ZnO & $\mathrm{ZnO} 0.5 \% \mathrm{w} / \mathrm{w}$ & Without ZnO & $\mathrm{ZnO} 0.5 \% \mathrm{w} / \mathrm{w}$ \\
\hline$C+$ Estel1000 & $10.9 \pm 0.7$ & $10.4 \pm 0.5$ & $7.1 \pm 0.7$ & $6.8 \pm 0.5$ & $4.4 \pm 0.4$ & $3.6 \pm 0.5$ \\
\hline$C+$ Silo111 & $5.0 \pm 0.7$ & $6.3 \pm 0.7$ & $1.8 \pm 1.0$ & $1.2 \pm 0.2$ & $4.4 \pm 0.4$ & $1.1 \pm 0.3$ \\
\hline$M+$ Estel 1000 & $12 \pm 2$ & $10.1 \pm 0.5$ & - & $5.9 \pm 1.0$ & $4.1 \pm 0.9$ & $2.9 \pm 0.7$ \\
\hline M+Silo111 & $5.4 \pm 0.5$ & $3.4 \pm 0.9$ & - & $1.5 \pm 0.3$ & $1.0 \pm 0.2$ & $1.0 \pm 0.2$ \\
\hline $\mathrm{G}+$ Estel1000 & $7.9 \pm 1.7$ & $10.2 \pm 0.8$ & $3.4 \pm 0.8$ & $5.8 \pm 1.2$ & $0.8 \pm 0.5$ & $2.8 \pm 1.5$ \\
\hline$G+$ Silo111 & $1.8 \pm 0.2$ & $4 \pm 3$ & $5 \pm 3$ & $2.5 \pm 0.6$ & $0.7 \pm 0.8$ & $0.7 \pm 0.4$ \\
\hline
\end{tabular}


$\mathrm{ZnO}-\mathrm{NPs}$ to Estel1000 seems to enhance cracking of the matrix (Fig. 1). A better performance was obtained for the $\mathrm{C}$ and $\mathrm{M}$ samples treated with Silo111/ZnO-NPs (Figs. 2, 3 ). The surfaces show homogeneously diffused whitish areas containing 2-20 $\mu \mathrm{m}$-clusters rich in zinc and silicon, similarly to what had previously been observed for stone samples treated with $\mathrm{Cu}-\mathrm{NPs} /$ Estel1100 [14]. The relative abundance of zinc with respect to calcium and silicon is lower in the Silo111 samples as compared to the Estel1000 ones. Interestingly, application of Silo111/ $\mathrm{ZnO}-\mathrm{NPs}$ on the $\mathrm{G}$ sample generates an even distribution of $1-10 \mu \mathrm{m}$ zinc grains; the relative abundance of zinc is higher than silicon, differently from what was observed for the $\mathrm{C}$ and $\mathrm{M}$ samples.

\section{In situ experimentation}

In situ experimentation represents a fundamental step of the testing and evaluation process of new conservation treatments. In this study, the developed materials were tested in carefully selected areas on the exterior of the San Leonardo di Siponto church (Manfredonia, Italy) (Fig. 4a). In particular, eight areas were considered. One area was left as such (see Fig. 4a, area A1). In all other areas the biofilm was removed by means of the application of commercially available biocides, typically quaternary ammonium salts, followed by mechanical cleaning (see "Experimental" section). Then, one of the cleaned areas was preserved (see Fig. 4b, area A2), while the other areas were respectively treated with Estel1100 (area B1), Silo111 (area B2), Estel1100 mixed with ZnO-NPs $(0.4 \% \mathrm{w} / \mathrm{w})$ (area C1), and Silo111 mixed with $\mathrm{ZnO}-\mathrm{NPs}$ $(0.4 \% \mathrm{w} / \mathrm{w})$ (area C2). On the remaining two areas (D1 and D) Estel1100/Cu-NPs (0.03\% w/w) and Silo111/CuNPs $(0.03 \% \mathrm{w} / \mathrm{w})$ were applied. The loadings for the $\mathrm{Cu}$ NPs-based nanocomposites are lower with respect to the ZnO-NPs-nanocomposites due to the fact that the former show a brownish colour, whereas the latter are white. The concentration $(0.03 \% \mathrm{w} / \mathrm{w})$ was decided on the basis of colorimetric data obtained for laboratory stone samples treated with differently loaded nanocomposites [14].

In order to evaluate eventual chromatic changes induced by the treatments, colorimetric data were acquired before and after (40 days and 6 months) application of the consolidant/water-repellent materials. The

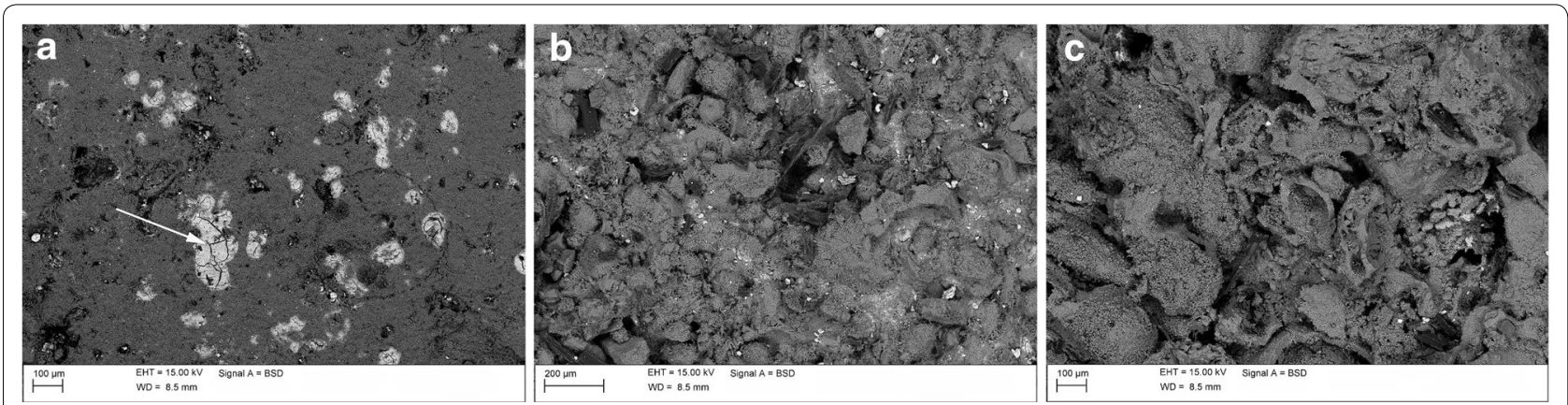

Fig. 1 SEM-EDS analyses of stone samples treated with Estel1000/ZnO-NPs (0.5\% w/w). a Calcare di Altamura; b Calcarenite di Gravina from Massafra; c Calcarenite di Gravina from Gravina
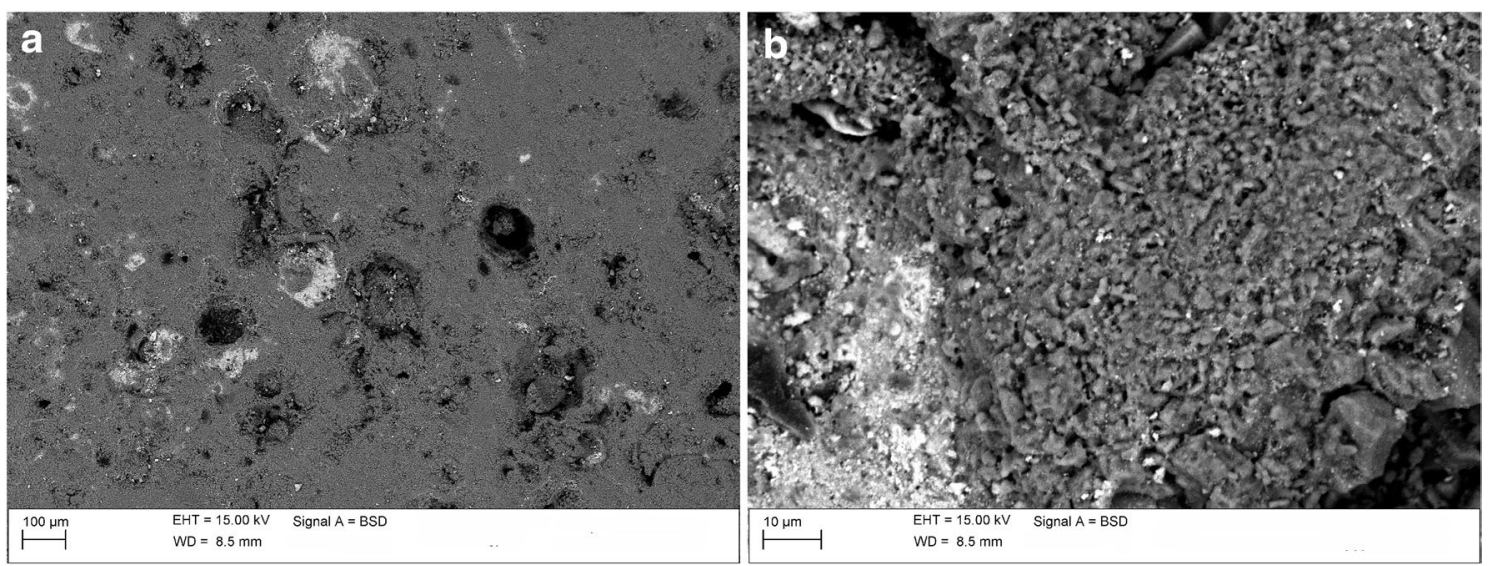

Fig. 2 SEM-EDS analyses of a Calcare di Altamura stone sample treated with Silo $111 / Z n O-N P s(0.5 \% \mathrm{~W} / \mathrm{W})$; b detail 

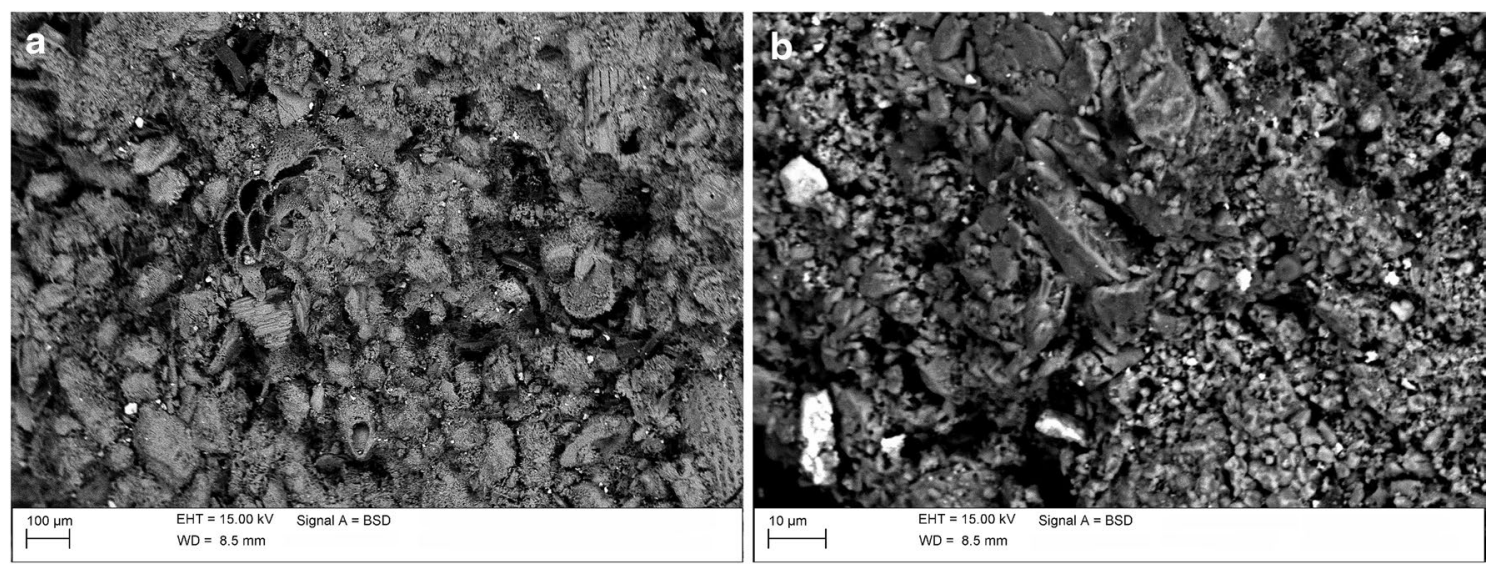

Fig. 3 SEM-EDS analyses of a Calcarenite di Gravina from Massafra stone sample treated with Silo111/ZnO-NPs (0.5\% w/w); b detail

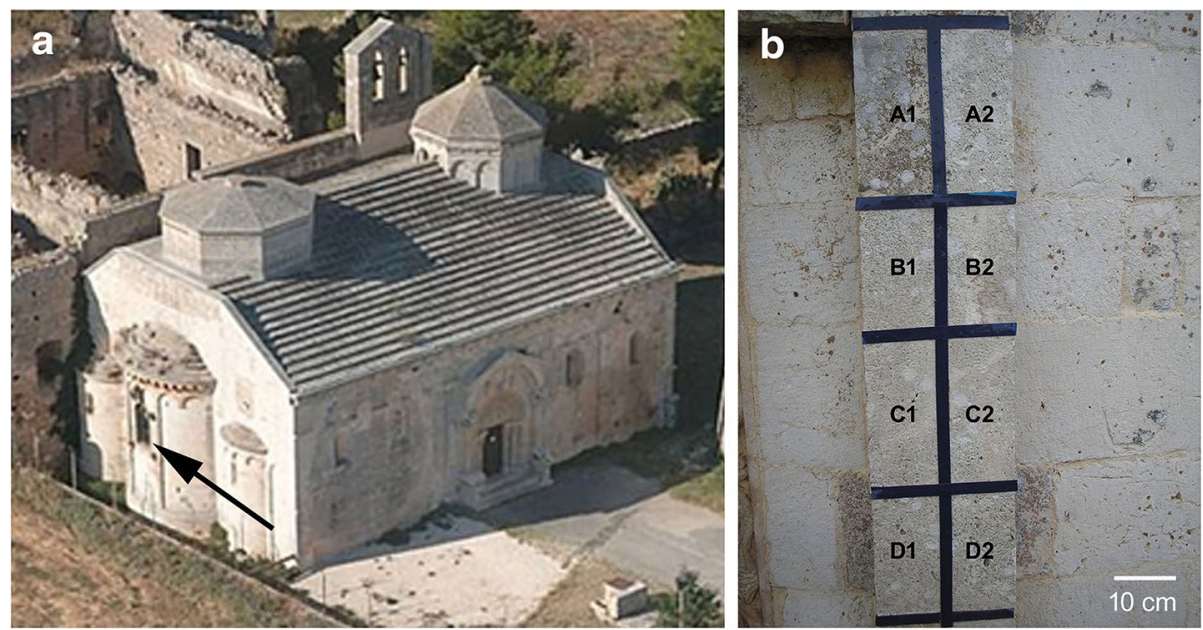

Fig. 4 In situ experimentation. a Exterior of the San Leonardo di Siponto church (Manfredonia, Italy) with indication of the test areas. b Test areas. A1 untreated area; $A 2$ cleaned area; B1 cleaned area treated with Silo 111; B2 cleaned area treated with Estel1 100; C1 cleaned area treated with Silo111/ZnO-NPs; C2 cleaned area treated with Estel1 100/ZnO-NPs; D1 cleaned area treated with Silo111/Cu-NPs; D2 cleaned area treated with Estel1100/Cu-NPs

chromatic change $(\Delta \mathrm{E})$ values, which were obtained as a medium of eight points for each area with their relative standard deviation, are reported in Fig. 5.

The relatively high standard deviations can be explained by the dishomogeneous characteristics of the stone substrate. The data relative to area A2, which was only cleaned but not treated with consolidant/water-repellent, are important so as to evaluate the intrinsic chromatic variations due to the stone substrate as such. The $\Delta \mathrm{E}$ values, which were obtained at 40 days and 6 months after treatment, are ca. 2 and seem to be rather constant, although, as already evidenced, the standard deviation is high. For all treated areas the $\Delta \mathrm{E}$ values range between 3 and 5 , which is below the $\Delta \mathrm{E}$ limit value $(\Delta \mathrm{E}=5)$ when chromatic changes become visible by the naked eye.

In particular, application of the consolidant/waterrepellents without nanoparticles led to slightly higher $\Delta \mathrm{E}$ values as compared to the untreated area. The addition of $\mathrm{ZnO}-\mathrm{NPs}$ or $\mathrm{Cu}-\mathrm{NPs}$ caused an additional increase of the chromatic changes both for Silo111 and Estel1100, which seems to diminuish or to be constant with time. However, after subtraction of the intrinsic chromatic variations of area A2, the chromatic changes that can be ascribed to the application of the materials are very low, i.e., below 3.5 and 1.5 after 40 days and after 6 months, respectively. Moreover, when considering the high standard deviation 


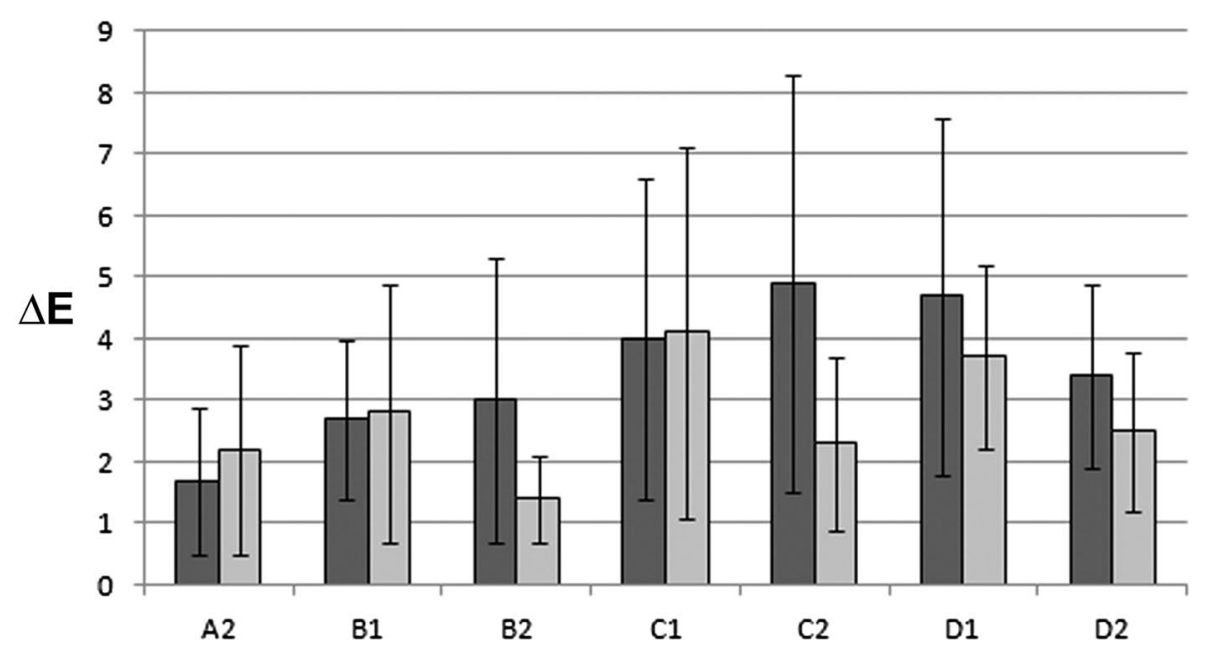

Fig. 5 Colour changes $(\Delta E)$ measured on the test areas at 40 days (dark grey bars) and 6 months (light grey bars) after the treatment. In each area the $\Delta \mathrm{E}$ values were averaged out for eight points to obtain a single value and standard deviation

values, the most important variations are most likely to be attributed to the dishomogeneity of the stone surface.

\section{Biological experiments}

Preliminary biological experiments were performed on Estel1100/ZnO nanocomposites in order to study their bioactive properties against Aspergillus niger, a ubiquitary fungus on stone monuments. The results show that only the control and the bare Estel1100 samples allowed for the growing of the Aspergillus, more or less in the same amount. All other samples, irrespective of the $\mathrm{ZnO}-\mathrm{NPs}$ loading, are completely clean.

\section{Experimental}

\section{Nanocomposites preparation}

Zinc oxide nanoparticles and copper nanoparticles, which were produced by means of an already reported electrochemical synthesis [12, 13, 30,31], were dispersed in Estel1000, Estel1100, and Silo111 (CTS, Altavilla Vicentina, Italy) to prepare nanocomposites. The procedure consisted in mixing the $\mathrm{ZnO}-\mathrm{NPs}$ white powder (or the $\mathrm{Cu}$-NPs colloid) with the consolidants/waterrepellents at various \% $\mathrm{w} / \mathrm{w}$ concentrations [11, 12, 14]. Estel1000, Estel1100, and Silo111 are ready-to-use materials dispersed in white spirit D40 and based on siloxane oligomers (Silo111-water-repellant), tetraethoxysilane (Estel1000-consolidant), and a combination of tetraethoxysilane and siloxane oligomers (Estel1100-consolidant/water-repellant). Since ethylsilicate is well known to undergo chemical modifications upon air exposure generating silica gel and ethanol, a period of at least 40 days of curing time was considered before any characterization [14].

\section{Stone samples}

Three calcareous stones from Apulia (south of Italy), that were used in the past and are still in use for construction and for restoration of historic monuments, were selected for samples preparation and petrographic characterization was performed. The first one is Calcare di Altamura (C), a biomicrite with well cemented grains in a carbonate mud and rather low porosity (ca. $3 \%$ ). The second stone was taken from a cave in Massafra and was classified as Calcarenite di Gravina (M), showing a micritic matrix containing carbonate grains and iron oxides, with a porosity ranging from 35 to $40 \%$. The third stone from a cave in Gravina could also be identified as a Calcarenite di Gravina (G). It is an organogenous calcarenite with a high porosity of ca. $50 \%$, which shows both lithoclasts and bioclasts. Samples were prepared by cutting square blocks with dimensions of $2.5 \times 2.5 \times 1 \mathrm{~cm}^{3}$ for the $\mathrm{Cal}$ care di Altamura, and quarters of a circle with $\mathrm{r}=2.5 \mathrm{~cm}$ and thickness of $1 \mathrm{~cm}$ for both Calcarenite di Gravina stone types. Estel1000, Silo111, Estel1000/ZnO (0.5 \% $\mathrm{w} / \mathrm{w})$, and Silo111/ZnO $(0.5 \% \mathrm{w} / \mathrm{w})$ were applied by brush up to complete imbibition on the samples, which were then kept at room temperature in a typical laboratory environment in order to allow for solvent evaporation and curing.

\section{Colorimetric measurements}

Evaluation of colour changes of the treated stone substrates was carried out by means of colorimetric measurements using a Konica-Minolta Chroma Metre (CM-2600d). The operating conditions were based on the "Raccomandazioni UNI Normal 43/93" [33]. The results were reported in the CIE-L*a*b* system. For each stone 
specimen, four (samples C) or three (samples M and G) points of analysis were selected; the instrument was set to automatically give the average value of the colorimetric coordinates $\left(\mathrm{L}^{*}, \mathrm{a}^{*}, \mathrm{~b}^{*}\right)$ of three measurements for each point. The resultant chromatic change $\Delta E^{*}$ was determined by means of the following equation:

$$
\Delta \mathrm{E}^{*}=\sqrt{ }\left(\Delta \mathrm{L}^{* 2}+\Delta \mathrm{a}^{* 2}+\Delta \mathrm{b}^{* 2}\right) .
$$

Then, for each sample the $\Delta \mathrm{E}$ values were averaged out to obtain a single value and standard deviation. Measurements were performed on the same points (by using a proper mask) before and after the remedy product application.

\section{SEM-EDS analyses}

Fragments of all treated and untreated stone samples were observed with an S360 SEM instrument (Cambridge Instruments) to evaluate the morphological modifications after nanocomposite application. The semi-quantitative elemental composition was obtained using an $\mathrm{X}$-ray energy-dispersive spectrometer with an OxfordLink Ge detector, equipped with a super atmosphere thin window with a thickness of $0.4 \mathrm{~mm}$. An accelerating voltage of $15 \mathrm{keV}$ and a beam current of $500 \mathrm{pA}$ were used. Before SEM-EDS investigations, specimens were coated with a $30 \mathrm{~nm}$ conductive graphite film.

\section{In situ experimentation}

Nanocomposites based on $\mathrm{ZnO}-\mathrm{NPs}$ and $\mathrm{Cu}-\mathrm{NPs}$ embedded in Estel1100 and Silo111 were applied on the external part of the apse of the 12th-century church of San Leonardo di Siponto (Manfredonia, Italy). The areas that were selected for experimentation are characterized by a homogeneous stone substrate, which is composed of sparitic fossiliferous limestone, and a compact and uniform biofilm. Eight areas (ca. $11 \times 23 \mathrm{~cm}^{2}$ ) were delimited for testing (see Fig. 4).

The first step consisted in the removal of the biofilm by means of a three-fold application of Preventol RI50/80, $\mathrm{N}, \mathrm{N}$-alkylbenzyl- $\mathrm{N}, \mathrm{N}$-dimethylammonium chloride (benzalkonium chloride) (CTS, Altavilla Vicentina, Italy) diluted in deionized water $(4 \% \mathrm{v} / \mathrm{v})$. Four days later, cleaning was carried out with scalpels, sponges, and brushes aided by the use of New Des, $N, N$-didecyl- $N, N$-dimethylammonium chloride (CTS, Altavilla Vicentina, Italy) in deionized water $(25 \% \mathrm{v} / \mathrm{v})$. Then, after a period of ca. 40 days in order to allow for complete drying of the surfaces, Silo111 and Estel1100 were applied two times by brush. These consolidant/water-repellents were used both as such and admixed with zinc oxide $(0.4 \% \mathrm{w} / \mathrm{w})$ and copper $(0.03 \% \mathrm{w} / \mathrm{w})$ nanoparticles, which were prepared by our research group $[14,32]$.
Chromatic changes were measured with spectrophotocolorimetry (see "Colorimetric measurements"), whereas biological colonization was monitored by applying biomolecular techniques (data not shown). Colorimetric measurements were performed at three different moments: (1) after removal of the biofilm and immediately before consolidant/water-repellent application, both as such (control) and as nanocomposite; (2) 40 days after application; (3) 6 months after application. In each area colorimetric data were collected in eight homogeneously distributed points and data treatment was performed by following the same procedure as used for the stone specimens (see "Colorimetric measurements").

\section{Biological experiments}

Some bioactivity tests were carried out with Aspergillus niger fungus as target microorganism. It was grown on Nutrient Agar (NA)-CM 0003 culture medium incubated at $37{ }^{\circ} \mathrm{C}$ for $48 \mathrm{~h}$. Different dilutions (from $10^{-1}$ to $10^{-9}$ ) were prepared and were then explored in the biological tests in order to choose the best experimental conditions. The nanocomposites applied on glass slides were immersed in bottles containing $20 \mathrm{~mL}$ of $10^{-5}$ dilution and were incubated at $35{ }^{\circ} \mathrm{C}$ for $24 \mathrm{~h} .1 \mathrm{~mL}$ of this solution was then plated and after another $24 \mathrm{~h}$ the colonies, if any present, were counted.

\section{Conclusions}

In this study nanostructured coatings based on zinc oxide nanoparticles embedded in commonly used consolidant/ water repellent materials were tested both on stone specimens and on site. Comparison could be made versus a previously developed, well performing $\mathrm{Cu}$-NPs based material. Application tests on calcareous stone specimens allowed to evaluate chromatic variations. For the $\mathrm{ZnO}-\mathrm{NPs}$ materials colour changes seem to be attenuated by the addition of zinc oxide, allowing for a relatively high NPs loading in the nanocomposite (ca. tenfold that of $\mathrm{Cu}$ system).

The SEM-EDS results obtained for surface fragments of the treated stone samples indicate a better penetration of Silo111 as compared to Estel1000, yielding minor chromatic variations. For all types of stone ZnO-NPs show a homogeneous distribution on the surface of the specimens.

In situ experimentation was undertaken by applying $\mathrm{Cu}$ - and $\mathrm{ZnO}$-nanocomposites on selected areas at the exterior of a medieval church. Chromatic variations, which were found to be already below limit values after 6 months of application, will be constantly monitored as well as the biological colonisation. 
Initial data on the bioactivity of the developed $\mathrm{ZnO}$ NPs materials indicated a successful inhibition of the growth of Aspergillus niger, already at low NPs concentrations.

These promising, although preliminary, results pave the way to the development of a material with remarkable long-lasting inhibition activity towards biofilm formation.

\section{Abbreviations}

NPs: nanoparticles; SEM: scanning electron microscopy; EDS: energy dispersive spectroscopy; XPS: X-ray photoelectron spectroscopy.

\begin{abstract}
Authors' contributions
IvdW carried out colorimetric measurements and SEM-EDS on the stone samples as well as the in situ experimentation and drafted the manuscript. ND performed the electrosynthesis of the Cu-NPs, prepared the nanocomposite materials, and helped to draft the manuscript. RC and MC set up and carried out the ZnO-NPs electrosynthesis and their TEM characterization. LS participated in the design and coordination of the study. All authors read and approved the final manuscript.
\end{abstract}

\section{Author details}

1 Dipartimento di Chimica, Università degli Studi di Bari "Aldo Moro", via Orabona 4, 70125 Bari, Italy. ${ }^{2}$ Centro Interdipartimentale "Laboratorio di ricerca per la diagnostica dei Beni Culturali", Università degli Studi di Bari "Aldo Moro", via Orabona 4, 70125 Bari, Italy.

\section{Acknowledgements}

The authors would like to thank Prof. Pasquale Acquafredda (Dipartimento di Scienze della Terra e Geoambientali, Università degli Studi di Bari "Aldo Moro", Italy) for petrographic characterization and for his precious assistance in the SEM-EDS analyses. This work was performed in the framework of the project PRIN 2010-11 "Sustainability in cultural heritage: from diagnosis to the development of innovative systems for consolidation, cleaning and protection" (Project No. 2010329WPF_001), funded by MIUR. The authors are grateful to the projects PO Puglia FESR 2007-13 "RESTAUREO" (3Z3VZ46) and PON03 "MAIND" (PE0004) for partial financial support.

\section{Compliance with ethical guidelines}

\section{Competing interests}

The authors declare that they have no competing interests.

Received: 7 October 2014 Accepted: 10 August 2015

Published online: 01 October 2015

\section{References}

1. Moreau C, Verges-Belmin V, Leroux L, Orial G, Fronteau G, Barbin V. Waterrepellent and biocide treatments: assessment of the potential combinations. J Cult Herit. 2008;9:394-400.

2. Urzi C, De Leo F. Evaluation of the efficiency of water-repellent and biocide compounds against microbial colonization of mortars. Int Biodeterior Biodegradation. 2007;60:25-34.

3. Leeming K, Moore CP, Denyer SP. The use of immobilised biocides for process water decontamination. Int Biodeterior Biodegradation. 2002:49:39-43.

4. Quaresima R, Baccante A, Volpe R, Corain B: Realisation and possibility of polymeric metalo-organic matrices with biocides activity. In: Moropoulou A, Zezza F, Kollias E, Rhodes, Technical Chamber of Greece (eds) Proceedings of the 4 th international Symposium on the Conservation of Monuments in the Mediterranean Basin. 2000;3, pp 323-35.

5. De Muynck W, Ramirez AM, De Belie N, Verstraete W. Evaluation of strategies to prevent algal fouling on white architectural and cellular concrete. Int Biodeterior Biodegradation. 2009;63:679-89.
6. Balzarotti-Kammlein R, Sansoni M, Castronovo A: An innovative water compatible formulation of ALGOPHASE ${ }^{\circledR}$ for treatment of mortars. In: Proceedings of the International Conference on Microbiology and Conservation of Microbes and Art, Florence; 1999, pp 217-20.

7. Blazquez AB, Lorenzo J, Flores M, Gomez-Alarcon G. Evaluation of the effects of some biocides against organisms isolated from historic monuments. Aerobiologia. 2000;16:423-8.

8. Pinna D, Salvadori O, Galeotti M. Monitoring the performance of innovative and traditional biocides mixed with consolidants and water-repellents for the prevention of biological growth on stone. Sci Total Environ. 2012;423:132-41.

9. Kapridaki $\mathrm{C}$, Maravelaki-Kalaitzaki P. $\mathrm{TiO}_{2}-\mathrm{SiO}_{2}-\mathrm{PDMS}$ nano-composite hydrophobic coating with self-cleaning properties for marble protection. Progress Org Coat. 2013;76:400-10.

10. Gómez-Ortíz N, De la Rosa-García S, González-Gómez W, Soria-Castro M, Quintana P, Oskam G, Ortega-Morales B. Antifungal coatings based on $\mathrm{Ca}(\mathrm{OH})_{2}$ mixed with $\mathrm{ZnO} / \mathrm{TiO}_{2}$ nanomaterials for protection of limestone monuments. ACS Appl Mater Interfaces. 2013;5:1556-65.

11. Cioffi N, Torsi L, Ditaranto N, Sabbatini L, Zambonin PG, Tantillo G, Ghibelli L, D'Alessio M, Bleve-Zacheo T, Traversa E. Antifungal activity of polymerbased copper nanocomposite coatings. Appl Phys Lett. 2004;85:2417-9.

12. Cioffi N, Torsi L, Ditaranto N, Tantillo G, Ghibelli L, Sabbatini L, BleveZacheo T, D'Alessio M, Zambonin PG, Traversa E. Copper nanoparticle/ polymer composites with antifungal and bacteriostatic properties. Chem Mater. 2005; 17:5255-62.

13. Cioffi N, Ditaranto N, Torsi L, Picca RA, De Giglio E, Sabbatini L, Novello L, Tantillo G, Bleve-Zacheo T, Zambonin PG. Synthesis, analytical characterization and bio-activity of Ag and Cu nanoparticles embedded in poly-vinyl-methyl-ketone films. Anal Bioanal Chem. 2005:382:1912-8.

14. Ditaranto N, Loperfido S, Van der Werf I, Mangone AR, Cioffi N, Sabbatini L. Synthesis and analytical characterisation of copper-based nanocoatings for bioactive stone artworks treatment. Anal Bioanal Chem 2011:399:473-81.

15. Wahab R, Mishra A, Yun SI, Kim YS, Shin HS. Antibacterial activity of ZnO nanoparticles prepared via non-hydrolytic solution route. Appl Microbiol Biotechnol. 2010;87:1917-25.

16. Lipovsky A, Nitzan Y, Gedanken A, Lubart R. Antifungal activity of Zn nanoparticles - the role of ROS mediated cell injury. Nanotechnology. 2011;22: 105101 (5 pp).

17. Selvam S, Sundrarajan M. Functionalization of cotton fabric with PVP/ZnO nanoparticles for improved reactive dyeability and antibacterial activity. Carbohydr Polym. 2012:87:1419-24.

18. Karunakaran C, Rajeswari V, Gomathisankar P. Antibacterial and photocatalytic activities of sonochemically prepared $\mathrm{ZnO}$ and $\mathrm{Ag}-\mathrm{ZnO}$. J Alloy Compd. 2010;508:587-91.

19. Padmavathy N, Vijayaraghavan R. Enhanced bioactivity of ZnO nanoparticles an antimicrobial study. Sci Technol Adv Mat. 2008;9: 035004 (7 pp).

20. McCarthy TJ, Zeelie JJ, Krause DJ. The antimicrobial action of zinc ion antioxidant combinations. J Clin Pharmacol Ther. 1992;17:51-4.

21. Zeelie JJ, McCarthy TJ. Effects of copper and zinc ions on the germicidal properties of two popular pharmaceutical antiseptic agents cetylpyridinium chloride and povidone-iodine. Analyst. 1998:123:503-7.

22. Zhou H, Wang X, Zhou Y, Yao H, Ahmad F. Evaluation of the toxicity of $\mathrm{ZnO}$ nanoparticles to Chlorella vulgaris by use of the chiral perturbation approach. Anal Bioanal Chem. 2014;406:3689-95.

23. Martins CT, Freire CSR, Neto CP, Silvestre AJD, Causio J, Baldi G, Sadocco P, Natércia TT. Antibacterial paper based on composite coatings of nanofibrillated cellulose and ZnO. Colloids Surf A. 2013;417:111-9.

24. Gordon T, Perlstein B, Houbara O, Felner I, Banin E, Margel S. Synthesis and characterization of zinc/iron oxide composite nanoparticles and their antibacterial properties. Colloids Surf A. 2011:374:1-8.

25. Jones N, Ray B, Ranjit KT, Manna AC. Antibacterial activity of ZnO nanoparticle suspensions on a broad spectrum of microorganisms. FEMS Microbiol Lett. 2008;279:71-6.

26. Huang L, Li DQ, Lin YJ, Wei M, Evans DG, Duan X. Controllable preparation of nano-MgO and investigation of its bactericidal properties. J Inorg Biochem. 2005;99:986-93.

27. Marciano FR, Lima-Oliveira DA, Da-Silva NS, Diniz AV, Corat EJ, Trava Airoldi VJ. Antibacterial activity of DLC films containing $\mathrm{TiO}_{2}$ nanoparticles. J Colloids Interface Sci. 2009:340:87-92. 
28. Zhang $L L$, Jiang $Y H$, Ding $Y L$, Daskalakis N, Jeuken L, Povey M, O'Neill AJ, York DW. Mechanistic investigation into antibacterial behaviour of suspensions of ZnO nanoparticles against E. coli. J Nanopart Res. 2010;121:1625-36.

29. El-Feky OM, Hassan EA, Fadel SM, Hassan ML. Use of ZnO nanoparticles for protecting oil paintings on paper support against dirt, fungal attack, and UV aging. J Cult Herit. 2013;15:165-72.

30. Chandrappa KG, Venkatesha TV, Vathsala K, Shivakumara C. A hybrid electrochemical-thermal method for the preparation of large $\mathrm{ZnO}$ nanoparticles. J Nanopart Res. 2010;12:2667-78.
31. Sportelli MC, Hötger D, Picca RA, Manoli K, Kranz C, Mizaikoff B, Torsi L, Cioffi N. Electrosynthesized Polystyrene Sulphonate-Capped Zinc Oxide Nanoparticles as Electrode Modifiers for Sensing Devices. Symposium K, MRS Spring Meeting Proceedings, 2014.

32. Ditaranto N, van der Werf I, Sportelli MC, Picca RA, Giannossa LC, Bonerba E, Tantillo G, Sabbatini L. Characterization and behaviour of ZnO-based nanocomposites designed for the control of biodeterioration of patrimonial stoneworks. New J Chem. 2015. doi:10.1039/C5NJ00527B.

33. Raccomandazioni NorMal 43/93/ Misure colorimetriche strumentali di superfici opache. Rome: CNR-ICR; 1993.

Publish with ChemistryCentral and every
scientist can read your work free of charge

"Open access provides opportunities to our colleagues in other parts of the globe, by allowing anyone to view the content free of charge."

W. Jeffery Hurst, The Hershey Company.

- available free of charge to the entire scientific community

- peer reviewed and published immediately upon acceptance

- cited in PubMed and archived on PubMed Central

- yours - you keep the copyright

Submit your manuscript here:

http://www.chemistrycentral.com/manuscript/

ChemistryCentral 